\title{
The Bolund Experiment, Part I: Flow Over a Steep, Three-Dimensional Hill
}

\author{
J. Berg • J. Mann - A. Bechmann - M. S. Courtney • \\ H. E. Jørgensen
}

Received: 17 November 2010 / Accepted: 6 July 2011 / Published online: 24 July 2011

(C) Springer Science+Business Media B.V. 2011

\begin{abstract}
We present an analysis of data from a measurement campaign performed at the Bolund peninsula in Denmark in the winter of 2007-2008. Bolund is a small isolated hill exhibiting a significantly steep escarpment in the main wind direction. The physical shape of Bolund represents, in a scaled-down form, a typical wind turbine site in complex terrain. Because of its small size the effect of atmospheric stratification can be neglected, which makes the Bolund experiment ideal for the validation of neutral flow models and hence model scenarios most relevant to wind energy. We have carefully investigated the upstream conditions. With a 7-km fetch over water, the incoming flow is characterized as flow over flat terrain with a local roughness height based on the surface momentum flux. The nearly perfect upstream conditions are important in forming a meaningful quantitative description of the flow over the Bolund hill. Depending on the wind direction, we find a maximum speed-up of $30 \%$ at the hill top accompanied by a maximum $300 \%$ enhancement of turbulence intensity. A closer inspection reveals transient behaviour with recirculation zones. From the wind energy context, this implies that the best site for erecting a turbine based on resource constraints unfortunately also imposes a penalty of high dynamic loads. On the lee side of Bolund, recirculation occurs with the turbulence intensity remaining significantly enhanced even at one hill length downstream. Its transient behaviour and many recirculation zones place Bolund in a category in which the linear flow theory is not applicable.
\end{abstract}

Keywords Atmospheric surface layer - Bolund - Complex terrain · Flow modelling · Turbulence · Wind energy

J. Berg $(\varangle) \cdot$ J. Mann · A. Bechmann · M. S. Courtney · H. E. Jørgensen The Wind Energy Department, Ris $\emptyset$ National Laboratory for Sustainable Energy/Technical University of Denmark (DTU), 4000 Roskilde, Denmark e-mail: jbej@risoe.dtu.dk 


\section{Introduction}

Atmospheric flow above complex terrain is our focus, and because wind turbines are increasingly erected in areas with complex orography, furthering the course of wind energy is the main impetus for the investigation. Good knowledge of the flow over complex terrain is essential for precisely estimating wind-energy potential, and assessing structural loads on turbines. An understanding of flow in complex terrain is also crucial for the parametrization of form drag in meteorological models. It is also significant for various dispersion applications.

Various atmospheric boundary-layer flow experiments have been performed over hills during the last thirty years with a main focus on hills with gentle slopes of less than 0.3 or $17^{\circ}$ (Walmsley and Taylor 1996). The experiments commenced in the 1970s with the investigation of flow over an escarpment on the Ris $\varnothing$ peninsula by Jensen and Peterson (1978) and in hilly terrain with inhomogeneous roughness by Sacré (1979). The escarpment experiment was followed by a more systematic and controlled experiment at the Hjardemaal escarpment, Denmark, where turbulence spectra were also measured (Emeis et al. 1993). Using the framework of the linear flow theory Taylor et al. (1987) summarized the early experiments on low hills. To a great extent the emphasis in the early years has been on the mean profiles of streamwise speed and turbulence intensity, whereas insight into the modification of turbulence structures by orography has been limited.

In the early 1980s, a well-known hill experiment was conducted by an international group on the Askervein Hill in the UK (Taylor and Teunissen 1983, 1984). The slope of that relatively smooth hill is generally less than $20^{\circ}$, with small areas reaching $30^{\circ}$, and the roughness was believed to be relatively uniform with the exception of a coastline several kilometres upstream. The mean wind profiles over Askervein have been extensively used for research with particular interest in the so-called linearized models, which assume the slopes to be gentle to avoid detachment and recirculation that are not captured by these models. The linear models (Jackson and Hunt 1975; Hunt et al. 1988) quite satisfactorily reproduce the measured speed-up on Askervein at the hilltop but perform less successfully on the lee side. An effective computational speed parameter, one of the strengths of linearized models, has led to their commercialization and availability for wind-energy resource estimation (Troen and Petersen 1989; Corbett et al. 2008). Velocity spectra from the Askervein Hill experiment have also been compared quite successfully to rapid distortion theory (RDT) predictions by Mann (2000), which builds on previous work by Britter et al. (1981) and Mann (1994).

Wind-tunnel investigations of the validity of linearized models show that they overestimate the speed-up over the tops of steep ridges (Athanassiadou and Castro 2001; Ayotte and Hughes 2004). Such an effect has led to overly optimistic predictions of power production and thus the economic feasibility of certain wind farms. Although rarely placed here, turbines downstream of steep hills have been known to suffer from excessive mechanical loads, caused by the unsteady wake of the hill. More commonly, turbines on the top of steep ridges with sub-ridges pointing away from the main ridge experience extremely large fluctuations in wind speed and direction, which can be detrimental to turbines. These deficiencies have stimulated research in non-linear atmospheric-flow models such as Reynolds-averaged Navier-Stokes solvers (RANS) and large-eddy simulation (LES). Again the Askervein experiment continues to serve well for comparison with these non-linear models (Castro et al. 2003; Lopes et al. 2007; Chow and Street 2009; Bechmann and Sørensen 2010).

Extremely steep or complex terrain is highly relevant to wind energy, however, simulating the flow is a challenge (Palma et al. 2008). We strongly believe that new atmospheric experiments addressing these types of terrains are essential for validating numerical models. 
The steep Bolund site gives rise to recirculation, stagnation and unsteady, erratic flow phenomena and is therefore well suited for such an experiment.

Planning was initiated toward a field campaign at the Bolund peninsula. Approvals from landowners and various public officials were obtained and the experimental design and logistics were planned. Masts were erected on site and a dedicated wireless network was established. The campaign proceeded from December 2007 through February 2008. In this study we present the results of the main analysis of these data. A secondary outcome of the Bolund campaign was an international workshop held in December 2009 at Ris $\varnothing$ DTU, in which more than 50 different numerical (both linearized, RANS and LES) and physical models were used in a blind comparison with the observations. These results are presented in Part II (Bechmann et al. 2011).

With the Bolund experiment we leave the realm of gentle slopes, and thus the applicability of the linear flow theory. In addition to the steep slopes present at Bolund, there is also a significant jump in local aerodynamic roughness that was not present in previous hill experiments. Thus Bolund provides challenges in more than one aspect, and we therefore believe that the experiment serves as a valuable benchmark for advanced, atmospheric-flow models. The high attendance at the workshop held at Ris $\varnothing$ DTU confirmed this belief.

Our paper begins with a section devoted to the physical characteristics of Bolund and a description of the instrumentation. In Sect. 3 we consider the upstream conditions, including local wind climate, sea fetch and stability. Section 4 presents one-point statistics of measurements, including mean wind, tilt, deflection and turbulence intensity along a transect. Turbulence structure is the focus of Sect. 5, and finally, a discussion and conclusions are presented in Sect. 6.

\section{Site and Instrumentation}

A photo of Bolund peninsula is shown in Fig. 1. Bolund is a natural hill 12-m tall $(h)$, 130-m long $(L)$, and 75-m wide $(W)$, located in Roskilde Fjord, Denmark, just north of Ris $\varnothing$ DTU $\left(55.7035^{\circ} \mathrm{N}, 12.0982^{\circ} \mathrm{E}\right)$. It is surrounded by water in all directions except to the east, where a narrow isthmus, submerged at times, leads to the mainland. From absolute water level readings in the harbours of Roskilde and Ris $\varnothing$, and from fixed time readings of relative water level on the platform itself, a time series of the absolute water level at the platform was constructed (Bechmann et al. 2009). During the measurement campaign the sea level

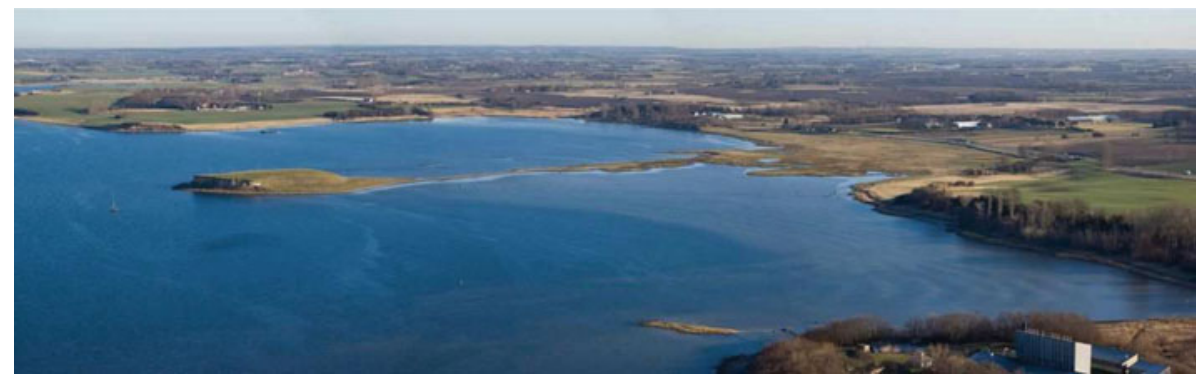

Fig. 1 The Bolund peninsula viewed from a 125-m tall meteorological mast located south of the site at Ris $\emptyset$ DTU. Westerly winds thus approach Bolund from the left 


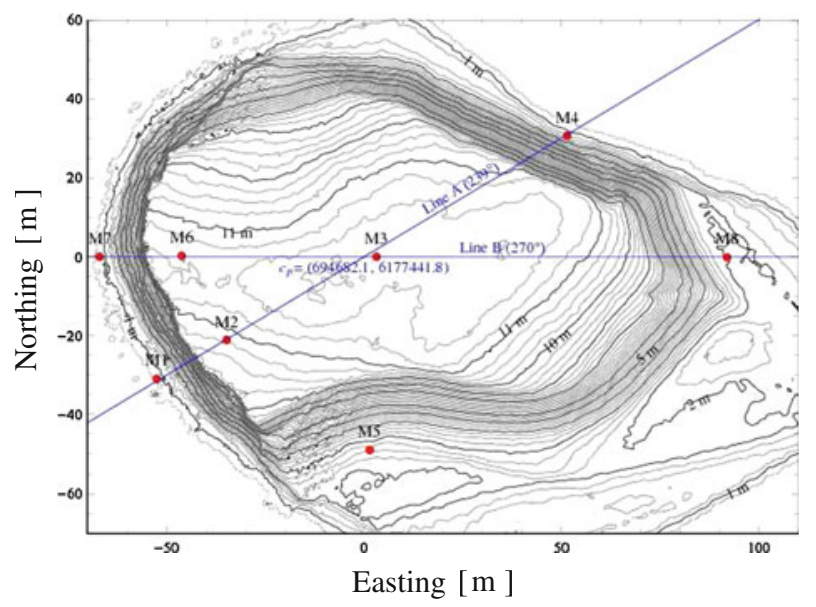

Fig. 2 A contour map of Bolund with meteorological masts denoted from M1 to M8 (see Sect. 2.2). A value of $0.75 \mathrm{~m}$ has been used for the water level in Roskilde fjord. The centre point, $C_{\mathrm{p}}=(0,0)$ is located at the position $(694682.1,6177441.8)$ in the UTM WGS84 zone 32 coordinate system. The map was created through airborne laser terrain mapping and a high resolution laser scanner positioned on the beach at Bolund. Two masts, M0 and M9, are not located in the map; they are located at positions $(-181.7,101.7)$ and $(327.3,-37.5)$; that is, to the left (west) and right (east) of Bolund, respectively

in Roskilde Fjord fluctuated $\approx 2 \mathrm{~m}$, covering the isthmus for a substantial fraction of the time.

The contour map in Fig. 2 gives an impression of the vertical escarpment to the west of Bolund. A slight overhang exists although not evident from the contour map, which is a very challenging feature for flow model resolution. In front of the escarpment, a small beach covered with small rocks is present. The top of Bolund consists of a relatively flat, welldefined plateau covered with grass. The slopes of the northern, southern and eastern sides are also steep with slopes of up to $40^{\circ}$, but here the crests are rounded. Except for the vertical escarpment and the narrow beach around the hill, Bolund is uniformly covered by grass. The corresponding roughness length is estimated at $z_{0}=0.015 \mathrm{~m}$, which was obtained by adapting neutral logarithmic wind profiles to measurements in Sect. 3. The roughness length of the surrounding water was much lower and can be (as seen in Sect. 3) described as in Charnock (1955). For model purposes we recommend $z_{0}=0.0003 \mathrm{~m}$. No larger roughness elements on the surface of Bolund have been deemed sufficiently important for individual treatment.

\subsection{Scale Effects}

In every respect Bolund is a small hill: the maximum height of Bolund is $12 \mathrm{~m}$, the length is approximately $150 \mathrm{~m}$, and the roughness length, $z_{0}$, varies from $0.0003 \mathrm{~m}$ over the water to $0.015 \mathrm{~m}$ over the hill itself. In this section we compare Bolund with a theoretical mesa-type hill with physical dimensions 10-30 times larger. Examples of such hills are often seen in Texas and other states in the USA with wind turbines typically situated near the edges. Bolund is therefore a relevant and realistic scenario for wind-energy purposes. Our goal is to investigate whether the flow around Bolund is geometrically similar to that around a significantly larger hill of the same shape. 
The geometry for the mesa hill is

$$
\begin{aligned}
h & \rightarrow 120-360 \mathrm{~m}, \\
L & \rightarrow 1500-4500 \mathrm{~m}, \\
z_{0} & \rightarrow 0.15-0.45 \mathrm{~m} .
\end{aligned}
$$

We first consider the Reynolds number, $R e_{\mathrm{h}}$, based on hill height. Reynolds number similarity implies Reynolds-number-independent flow solutions and is the foundation of turbulent viscosity and Reynolds stress modelling (Pope 2000). However, recent studies conducted in a wind tunnel have shown that the Reynolds number must be very high to obtain independence regarding bluff bodies in a turbulent boundary flow with concentrated vortex motion (Lim et al. 2007). The Reynolds number in the Bolund case is $R e_{\mathrm{h}}=U h / v \approx 10^{7}$ with $U=10 \mathrm{~m} \mathrm{~s}^{-1}$. This is somewhat larger than the maximum range of up to $R e_{\mathrm{h}} \approx 10^{6}$ investigated by Lim et al. (2007) in a somewhat different flow case. Even at this large number, variation was observed in surface parameters such as pressure and speed as a function of the Reynolds number. We therefore cannot completely rule out that some dependence (vanishing maybe) on the Reynolds number is present at Bolund. The same argument can be applied to the mesa hill, although with less probability.

The inner length scale, $\ell_{\mathrm{i}}$, characterizes the height over the terrain for which turbulent stresses dominate the flow. The relationship of Jensen et al. (1984) is, for a small hill where the size, $L \gg h$,

$$
\ell_{\mathrm{i}} \log ^{2}\left(\ell_{\mathrm{i}} / L\right)=0.3 L
$$

For Bolund we estimate, $\ell_{\mathrm{i}} \approx 2 \mathrm{~m}\left(21-63 \mathrm{~m}\right.$ for the mesa). Strictly speaking, $\ell_{\mathrm{i}}$ makes sense only for gently sloping hills; therefore we may not necessarily expect the turbulence intensity to peak this close to the surface.

When up-scaling Bolund to the mesa, the influence of atmospheric stability and the height of the atmospheric boundary-layer, $z_{i}$ is more important. In the case of Bolund, $h \ll z_{i}$ and $h \ll L_{\mathrm{MO}}$ ( $L_{\mathrm{MO}}$, the Obukhov length is defined in Eq. 2$)$; therefore we may expect the perturbations on the flow induced by the hill to be larger than those caused by changes in stability. For all practical purposes, we can treat the atmosphere as neutral. However, this application may not be appropriate for the mesa. In neutral situations in which the wind speed is very high and in highly unstable situations in which $z_{i}$ is very high, stability may be neglected. However, in stable situations, where $z_{i}$ tends to be very low and comparable with $h$, strong effects of stratification are expected; thus the generalization from Bolund to the mesa fails.

The final effect we consider is the influence of the Coriolis force. For the vertical direction, we can repeat the proceeding arguments because the Ekman depth generally is similar in size to the atmospheric boundary-layer height. Turning of the wind with height could interfere with the mesa-hill perturbations in at least stably stratified situations, while it can be neglected in the Bolund case. For the horizontal direction we consider the Rossby number, $R o=U / f L$, where $f$ is the Coriolis parameter $\left(f \approx 10^{-4} \mathrm{~s}^{-1}\right.$ for mid-latitudes). For Bolund, $R o=667$. Because this value is much larger than one, Coriolis effects can be neglected. For the mesa, however, $R o \approx 20-60$, and Coriolis effects may be significant.

\subsection{Instrumentation}

The masts are positioned on two main transects: line A and B in Fig. 2. The eight red dots denoted as M1-M8 represent the mast positions. Two additional masts were erected, 
to measure an undisturbed approach flow. M0 was located on a jack-up platform to the west of Bolund, while M9 was located on a small beach east of the isthmus east of Bolund.

To resolve the wind in all three directions we have primarily employed sonic anemometers. We have used Metek USA 1-Basic sonics with two-dimensional head correction (http://www. metek.de/). At a sampling rate of $20 \mathrm{~Hz}$, a good signal-to-noise ratio, and an almost negligible flow distortion, they provide acceptable mean and turbulence measurements. The sonic anemometers provide data with a two-dimensional head correction, which is a function of only the azimuth angle. Therefore, to account for realistic flow angles, we have post-processed the measurements with a three-dimensional head correction, which is a function of the azimuth and tilt angle, given by Metek (2004). This measure was assigned utmost importance in the present measurement campaign. Validation of the corrections is given in Bechmann et al. (2009) and Dellwik et al. (2010a). The 10 masts were instrumented as detailed in Table 1. On the upstream masts, M0 and M9, as well as higher aloft we have installed cup anemometers of the type Wind Sensor P2546 "Risø" cup anemometer (http://www.cupanemometer.com/ products.htm).

Table 1 Mast instrumentation

\begin{tabular}{|c|c|c|c|c|c|c|}
\hline Instr. ID & $z_{\mathrm{agl}}(\mathrm{m})$ & $x(\mathrm{~m})$ & $y(\mathrm{~m})$ & $z(\mathrm{~m})$ & Start & End \\
\hline M0_Cup_2 & - & -183.5 & -102.7 & 3.1 & 211207 & 250208 \\
\hline M0_Cup_5 & - & -180.8 & -103.3 & 6.1 & 211207 & 250208 \\
\hline M0_Cup_9 & - & -180.8 & -103.3 & 10.1 & 211207 & 250208 \\
\hline M0_Cup_15 & - & -181.7 & -101.7 & 16.1 & 211207 & 250208 \\
\hline M0_S_5 & - & -181.3 & -102.5 & 6.1 & 211207 & 250208 \\
\hline M0_S_12 & - & -180.8 & -103.3 & 13.1 & 100108 & 250208 \\
\hline M0_Tabs_2 & - & -180.8 & -103.3 & 3.1 & 211207 & 250208 \\
\hline M0_Tdiff_12_2 & - & -180.8 & -103.3 & $3.1-13.1$ & 211207 & 250208 \\
\hline M0_Tsurf & - & -180.8 & -103.3 & - & 211207 & 250208 \\
\hline M0_Twater & - & -180.8 & -103.3 & - & 211207 & 250208 \\
\hline M1_S_2 & 2.1 & -52.4 & -31.0 & 2.8 & 211207 & 250208 \\
\hline M1_S_5 & 5.1 & -52.4 & -31.0 & 5.8 & 211207 & 250208 \\
\hline M1_S_9 & 9.0 & -52.4 & -31.0 & 9.8 & 211207 & 250208 \\
\hline M0_Tdiff_9_2 & $2.1-9.0$ & -52.9 & -29.2 & $2.8-9.8$ & 211207 & 250208 \\
\hline M2_Cup_9 & 9.1 & -34.8 & -21.1 & 19.9 & 211207 & 240108 \\
\hline M2_Cup_11 & 11.1 & -34.9 & -19.3 & 21.9 & 240108 & 250208 \\
\hline M2_S_1 & 1.1 & -34.8 & -21.1 & 11.9 & 211207 & 250208 \\
\hline M2_S_2 & 2.1 & -34.9 & -20.2 & 12.9 & 211207 & 250208 \\
\hline M2_S_3 & 3.6 & -34.8 & -21.1 & 14.4 & 140108 & 250208 \\
\hline M2_S_5 & 5.1 & -34.8 & -21.1 & 15.9 & 211207 & 250208 \\
\hline M2_S_9 & 9.1 & -34.8 & -21.1 & 19.9 & 240108 & 250208 \\
\hline Zephir unit 102 & 0.0 & -34.8 & -27.8 & 10.8 & 280108 & 150208 \\
\hline M3_S_9 & 9.0 & 3.1 & 3.6 & 20.6 & 211207 & 250208 \\
\hline M3_S_2 & 2.0 & 3.2 & 0.0 & 13.6 & 211207 & 250208 \\
\hline M3_S_5 & 5.0 & 3.2 & 0.0 & 16.6 & 211207 & 250208 \\
\hline M3_S_9 & 9.0 & 3.2 & 0.0 & 20.6 & 240108 & 250208 \\
\hline
\end{tabular}


Table 1 continued

\begin{tabular}{|c|c|c|c|c|c|c|}
\hline Zephir unit 102 & 0.0 & 3.2 & -10.0 & 11.7 & 150208 & 250208 \\
\hline M4_S_2 & 1.4 & 51.5 & 30.6 & 2.8 & 211207 & 250208 \\
\hline M4_S_5 & 4.4 & 51.5 & 30.6 & 5.8 & 211207 & 250208 \\
\hline M4_S_9 & 8.4 & 51.5 & 30.6 & 9.8 & 211207 & 250208 \\
\hline M5_S_2 & 2.2 & 1.5 & -48.9 & 4.8 & 211207 & 240108 \\
\hline M5_S_5 & 5.2 & 1.5 & -48.9 & 7.8 & 211207 & 240108 \\
\hline M6_Cup_9 & 8.9 & -46.1 & 0.2 & 20.4 & 211207 & 250208 \\
\hline M6_S_2 & 1.9 & -46.1 & 0.2 & 13.3 & 211207 & 250208 \\
\hline M6_S_5 & 4.9 & -46.1 & 0.2 & 16.4 & 211207 & 250208 \\
\hline M7_S_2 & 2.0 & -66.9 & 0.0 & 2.8 & 211207 & 250208 \\
\hline M7_S_5 & 5.0 & -66.9 & 0.0 & 5.8 & 211207 & 250208 \\
\hline M8_Cup_9 & 8.8 & 92.0 & -0.1 & 10.8 & 211207 & 250208 \\
\hline M8_S_2 & 1.8 & 92.0 & -0.1 & 3.8 & 211207 & 250208 \\
\hline M8_S_5 & 4.7 & 92.0 & -0.1 & 6.8 & 211207 & 250208 \\
\hline M9_Cup_2 & 1.9 & 327.3 & -39.3 & 3.3 & 211207 & 250208 \\
\hline M9_Cup_5 & 5.0 & 327.3 & -39.3 & 6.4 & 211207 & 250208 \\
\hline M9_Cup_9 & 9.0 & 327.3 & -39.3 & 10.4 & 211207 & 250208 \\
\hline M9_Cup_15 & 15.6 & 327.3 & -39.3 & 17.0 & 211207 & 250208 \\
\hline M9_S_5 & 5.0 & 327.3 & -38.4 & 6.4 & 211207 & 250208 \\
\hline Zephir unit 2 & 0.0 & 327.3 & -49.3 & 1.4 & 211207 & 250208 \\
\hline M9_Tdiff_14_2 & $1.9-14.0$ & 327.3 & -39.3 & $3.3-15.4$ & 231207 & 250208 \\
\hline
\end{tabular}

The instrument identity is as follows: MX is the mast, number X, with "Cup" denoting cup anemometer, "S" sonic anemometer, and "T" temperature sensors. For the latter case, Tdiff_ $z_{1} z_{2}$ is the difference between the two heights $z_{1}$ and $z_{2}$, while $\mathrm{Tabs}_{z}$ is the absolute temperature measured at height $z$. Tsurf and Twater are water temperature at the surface and below, respectively. The instruments ZephIR unit 102 and unit 2 are lidars. The height $z_{\mathrm{agl}}$ is the height above ground level. No numbers are given for Mast M0 because the water level fluctuates. The name extension corresponds to the approximate height above water level. $x$ is easting, $y$ is northing, and $z$ is height in the local coordinate system. Start and End denote the time of operation for the given instrument. The time format is given by DDMMYY

Table 2 Boom directions

\begin{tabular}{lcccccccccc}
\hline Mast ID & M0 & M1 & M2 & M3 & M4 & M5 & M6 & M7 & M8 & M9 \\
\hline Boom direction & $151^{\circ}$ & $179^{\circ}$ & $179^{\circ}$ & $175^{\circ}$ & $180^{\circ}$ & $175^{\circ}$ & $179^{\circ}$ & $180^{\circ}$ & $180^{\circ}$ & $178^{\circ}$ \\
\hline
\end{tabular}

Absolute temperature was measured on mast M0 and M9 using passively ventilated radiation screens and a Pt100 sensor (Risø P2449A). Furthermore, we measured temperature differences between two layers by Ris $\varnothing$ Pt500 sensors. Sensible heat fluxes were obtained from sonic anemometers. All instruments were installed on booms $1.8 \mathrm{~m}$ long and oriented as detailed in Table 2.

To study the feasibility of wind lidars in complex terrain, two ZephIR lidars were deployed, though the analysis of these data falls outside the scope of the present work, see Dellwik et al. (2010b). Further details on the technical aspects of the campaign can be found in Bechmann et al. (2009). 


\section{Upstream Conditions}

The importance of characterizing the upstream conditions appears quite obvious. For modelling purposes, the inflow conditions should be known in advance. Hunt et al. (1978) determined that the surface stagnation point downstream of a bluff body approaches the bluff body when the inflow changes from laminar to turbulent. The same was observed by Castro and Robins (1997) in a wind tunnel, who discovered that the addition of turbulence and shear considerably reduced the size of the recirculation zone behind the bluff body. It is not possible for us to investigate these findings with respect to Bolund because conditioning the inflow based on the profile and turbulence would require a much longer measurement period with a higher variety of meteorological conditions and a larger number of masts deployed in the wake of Bolund.

\subsection{Stability and Wind Climate}

Mast M0 was located in the fjord $150 \mathrm{~m}$ away from Bolund, which is approximately one hill length away. For westerly winds, the measurements at M0 were influenced to some degree by the presence of Bolund. From numerical simulations, Bechmann et al. (2011) estimated the speed-down at $\mathrm{M} 0$ to be $\approx 0.5 \%$. We can thus use $\mathrm{M} 0$ to characterize the incoming flow. On the contrary, other geographical features in addition to Bolund will affect the incoming flow. According to the fetch over water, we have divided westerly winds into three classes. When the flow is from $180^{\circ}$ to $220^{\circ}$, the water fetch is approximately $0.8 \mathrm{~km}$, a point at which various buildings and trees on the Ris $\varnothing$ DTU premises to the south will most likely affect the turbulence intensity. Flow at $225^{\circ}-250^{\circ}$ has a fetch length of approximately $4 \mathrm{~km}$, while flow at $260^{\circ}-300^{\circ}$ has a fetch of approximately $7 \mathrm{~km}$, with the upstream land mostly covered by beech trees. A maximum angle of $300^{\circ}$ has been chosen to avoid mast shadow effects. For example Table 2 shows the boom direction at M0 to be $151^{\circ}$.

The left panel of Fig. 3 shows the wind direction as measured with a sonic located at $5 \mathrm{~m}$ at M0. Grey shading in the figure illustrates that the vast majority of winds were from westerly and south-westerly directions and fell within the three fetch classes previously defined. For a short time, the wind was from the south to east, while northern winds were nearly absent in the measurement period.

The campaign was designed for westerly and south-westerly winds and transects were chosen accordingly. The data coverage is excellent and the upstream conditions were ideal. The upstream conditions for easterly winds were difficult to characterize because of
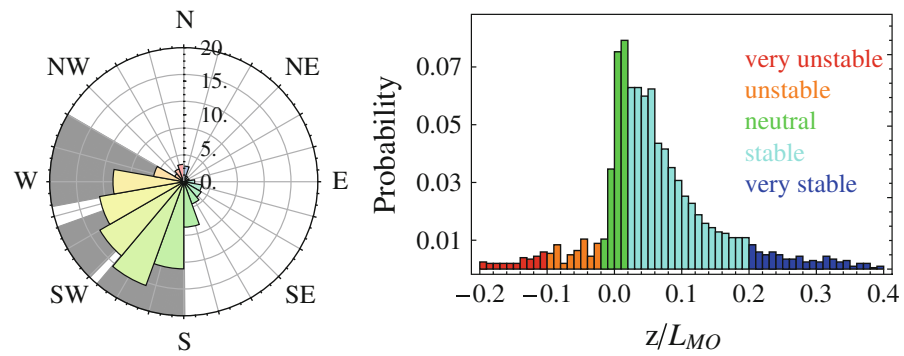

Fig. 3 Left: Distribution of wind directions at Mast M0 at $5 \mathrm{~m}$. Numbers denote probability in percentage, while the grey areas sweep the three fetch classes. Right: Histogram of five different stability classes. The data, 30-min averages, are from Mast M0 at $5 \mathrm{~m}$ 
insufficient data and a quite inhomogeneous terrain in that direction. For these reasons, we now consider winds only from the west.

The stability at M0 is characterized by the Obukhov length (measured at $5 \mathrm{~m}$ )

$$
L_{\mathrm{MO}}=-\frac{u_{\star}^{3}}{\kappa(g / \theta) \overline{w^{\prime} \theta^{\prime}}},
$$

where the friction velocity, $u_{\star}$, is defined by

$$
u_{\star}=\left|\overline{u^{\prime} w^{\prime}}\right|^{1 / 2} \text {. }
$$

In the preceding equations and for all future references, $u$ is the magnitude of the horizontal mean wind vector and $w$ is the mean wind in the true vertical direction, while primed quantities are fluctuations around these values. $\theta$ is the potential temperature, and the covariance $\overline{w^{\prime} \theta^{\prime}}$ is directly obtained from sonic measurements. If nothing else is stated, mean values correspond to 30-min averages, $g$ is the acceleration due to gravity, here, taken to be $9.82 \mathrm{~m} \mathrm{~s}^{-2}$, and $\kappa=0.4$ is the von Karman constant.

In the right panel of Fig. 3 we have plotted probability histograms of the dimensionless parameter $z / L_{\mathrm{MO}}$. Five stability classes were defined: very unstable $\left(1 / L_{\mathrm{MO}} \leq-0.02\right)$, unstable $\left(-0.02<1 / L_{\mathrm{MO}}<-0.004\right)$, neutral $\left(\left|1 / L_{\mathrm{MO}}\right| \leq 0.004\right)$, stable $(0.004<$ $\left.1 / L_{\mathrm{MO}}<0.04\right)$ and very stable $\left(1 / L_{\mathrm{MO}} \geq 0.04\right)$. The majority of data were generally in the neutral or slightly stable regimes.

\subsection{Mean Wind Profiles}

The bulk Richardson number is defined as

$$
R i_{\mathrm{b}}=\frac{g \Delta \theta \Delta z}{T(\Delta u)^{2}}
$$

where $\Delta \theta$ is the potential temperature difference between 2 and $12 \mathrm{~m}$ and $T$ is evaluated at $2 \mathrm{~m}$. $\Delta u$ is the mean wind difference, $\Delta u=\left(u_{15 \mathrm{~m}}+u_{9 \mathrm{~m}}\right) / 2-u_{2 \mathrm{~m}}$.

In Fig. $4 R i_{\mathrm{b}}$ is plotted as a function of $z / L_{\mathrm{MO}}$. The three panels represent the three fetch classes according to wind direction with fetch in parentheses: $180^{\circ}-220^{\circ}(0.8 \mathrm{~km})$, $225^{\circ}-250^{\circ}(4 \mathrm{~km})$ and $260^{\circ}-300^{\circ}(7 \mathrm{~km})$. The dashed black line in all three panels represents the Monin-Obukhov empirical relations for flow over flat homogeneous terrain (Kaimal and Finnigan 1994).

$$
R i\left(z / L_{\mathrm{MO}}\right) \equiv\left(\frac{z}{L_{\mathrm{MO}}}\right) \frac{\phi_{\mathrm{h}}\left(z / L_{\mathrm{MO}}\right)}{\phi_{\mathrm{m}}\left(z / L_{\mathrm{MO}}\right)^{2}}= \begin{cases}z / L_{\mathrm{MO}} & z / L_{\mathrm{MO}}<0 \\ \left(z / L_{\mathrm{MO}}\right)\left(1+5 z / L_{\mathrm{MO}}\right)^{-1} & z / L_{\mathrm{MO}} \geq 0\end{cases}
$$
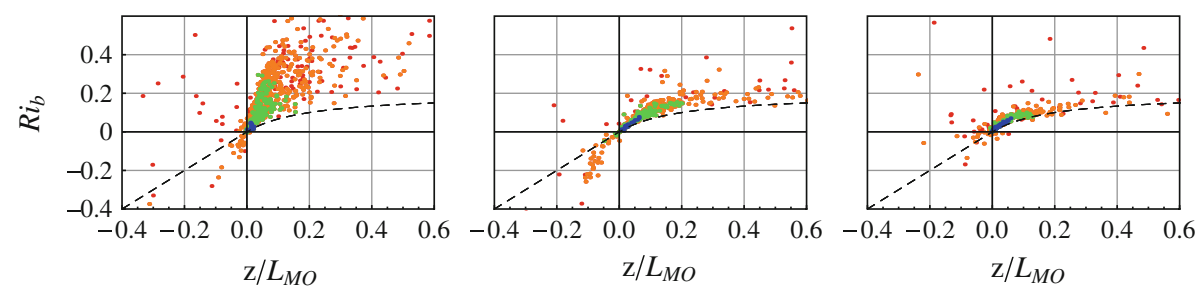

Fig. 4 The bulk Richardson number, $R i_{\mathrm{b}}$ as a function of $z / L_{\mathrm{MO}}$ for wind from the west. The left, middle, and right panels represent the three fetch classes: $0.8,4$, and $7 \mathrm{~km}$, respectively. The different colours refer to wind speeds: $u_{5 \mathrm{~m}}<4 \mathrm{~m} \mathrm{~s}^{-1}$ (red), $4 \mathrm{~m} \mathrm{~s}^{-1}<u_{5 \mathrm{~m}}<8 \mathrm{~ms}^{-1}$ (orange), $8 \mathrm{~ms}^{-1}<u_{5 \mathrm{~m}}<12 \mathrm{~ms}^{-1}$ (green) and $12 \mathrm{~ms}^{-1}<u_{5 \mathrm{~m}}$ (blue). The dashed curve is Eq. (5) 
In the preceding equation, $\phi_{\mathrm{h}}\left(z / L_{\mathrm{MO}}\right)$ and $\phi_{\mathrm{m}}\left(z / L_{\mathrm{MO}}\right)$ are non-dimensional stability functions for heat and momentum, respectively, and in principle, are based on the gradient Richardson number and not the bulk Richardson number used here. For a short fetch (top left), there is no collapse between data and the empirical relations. For a higher fetch (top right and bottom left), the collapse is good. Another trend is that for increasing wind speeds (green to blue), data cluster around $z / L_{\mathrm{MO}}=0$, which indicates neutral stability.

For the longest fetch $(7 \mathrm{~km})$ the well-known logarithmic wind profile

$$
\frac{u}{u_{\star}}=\frac{1}{\kappa} \log \left(\frac{z}{z_{0}}\right)
$$

is found with $z_{0}=0.0008 \mathrm{~m}$ for constant $\kappa=0.4 ; z$ is the height above the surface, which is not constant because of the varying sea level. We have therefore used a time-dependent value in the various profiles giving rise to the fit. Because the platform causes a small speed-up close to the water, we have not included data from the cup anemometer at $2 \mathrm{~m}$ and at $5 \mathrm{~m}, 3 \%$ speed-up and $1 \%$ speed-up, respectively, in the fits.

Because the dominant fetch is over water we might expect $z_{0}$ to be a function of $u_{\star}$, which according to Charnock (1955), is given by $z_{0}=\alpha_{\mathrm{c}} u_{\star}^{2} / g$, where $\alpha_{\mathrm{c}}$ is the Charnock constant. For the two longest fetches we found excellent agreement with constants, $\alpha_{\mathrm{c}}$, being 0.025 and 0.030, respectively. Compared with the open sea all values were rather large (Geernaert 1997), probably due to the limited fetch and shallow water depth in Roskilde Fjord.

\subsection{Variances and Covariances}

Turbulence can be roughly quantified as second-order moments of velocity fluctuations with the turbulence intensity defined as

$$
I_{u} \equiv \frac{\sqrt{\overline{u^{\prime} u^{\prime}}}}{u}
$$

A plot of $I_{u}$ measured at $5 \mathrm{~m}$ at M0 is presented in the left panel of Fig. 5 with the other two components: transverse $\sqrt{\overline{v^{\prime} v^{\prime}}} / u$ and vertical $\sqrt{\overline{\overline{w^{\prime} w^{\prime}}}} / u$. For wind from the south, it is evident that all three intensities are increased in comparison to the longer fetch directions, which must be caused by the buildings and trees on the Ris $\varnothing$ peninsula. For covariances, only $\overline{u^{\prime} w^{\prime}} / u^{2}$ is significantly enhanced corresponding to a larger $u_{\star}$, whereas the components orthogonal to the mean wind direction are constant, albeit with widespread scatter. Another interesting feature is the positive nature of $\overline{v^{\prime} w^{\prime}}$. In a perfect reflection symmetric case, this quantity should be zero. However, this is not the case. The value of $\left|\overline{v^{\prime} w^{\prime}}\right|$ is approximately $30 \%$ of $\left|\overline{u^{\prime} w^{\prime}}\right|$, and hence not negligible. Because a misalignment of sonic instruments would give rise to a directional dependence, which is also not the case here, we attribute the positive nature to physical processes, especially the Coriolis force and its Ekman spiralling cross-isobaric flow close to the surface. This matter will be studied in more detail in a future study.

\subsection{Spectra}

To obtain a deeper insight into the turbulence structure of the inflow, we calculated the spectra from the $20 \mathrm{~Hz}$ sonic data from Mast M0 at $5 \mathrm{~m}$. We calculate the two-sided time spectrum, $S_{u_{i}}(f)$, 

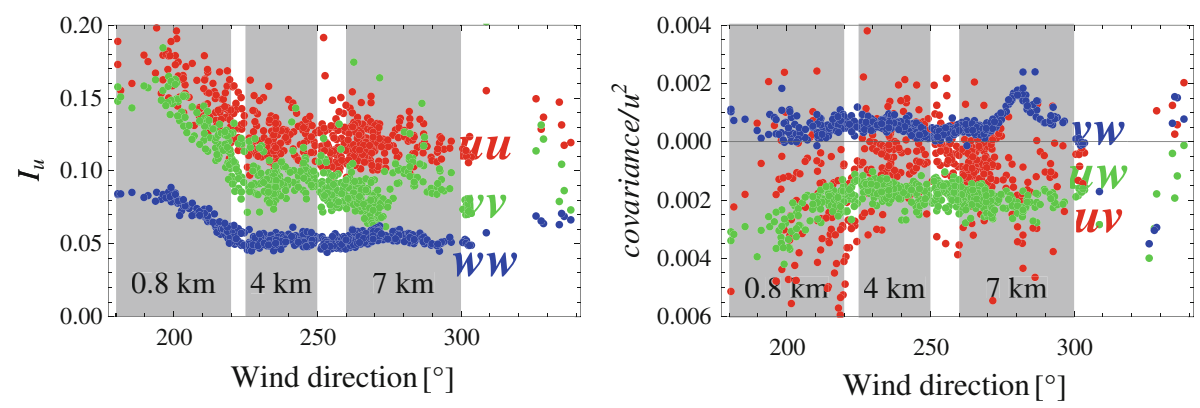

Fig. 5 Turbulence at Mast M0. Left: turbulence intensity $I_{u}$ as a function of wind direction with $\overline{u^{\prime} u^{\prime}}$ (red), $\overline{v^{\prime} v^{\prime}}$ (green) and $\overline{w^{\prime} w^{\prime}}$ (blue). Right: covariance. $\overline{u^{\prime} v^{\prime}}($ red $), \overline{u^{\prime} w^{\prime}}$ (green), and $\overline{v^{\prime} w^{\prime}}$ (blue)

$$
S_{u_{i}}(f) \propto\left|\hat{u_{i}}(f)\right|^{2},
$$

where $\hat{u}_{i}(f)$ is the Fourier transform of $u_{i}(t)$, and $f$ is the frequency in Hz. Two-sided refers to the normalization

$$
\sigma_{u_{i}}^{2}=\int_{-\infty}^{\infty} S_{u_{i}}(f) \mathrm{d} f,
$$

with $\sigma_{u_{i}}^{2}$ as the variance of the time series, $u_{i}(t)$. Plotted with a logarithmic $x$-axis and normal $y$-axis half the variance equals the area under the graph. We have only used wind speeds between 10 and $14 \mathrm{~m} \mathrm{~s}^{-1}$. We used frequency domain ensemble averaging to reduce the scatter of the estimated spectrum (for a rigorous treatment, see Pope 2000).

All calculated spectra were multiplied by $f / u_{\star}^{2}$ and plotted as a function of the nondimensional frequency $n=f z / u$. The latter represents the ratio $z$ to $e d d y$ wavelength $u / f$, which assumes the validity of Taylor's hypothesis.

In Fig. 6 we present the spectra $S_{u}(f), S_{v}(f)$, and $S_{w}(f)$ and the cospectrum $S_{u w}(f)$ for the three fetch classes. The Kaimal model spectra (Kaimal and Finnigan 1994) are superposed in similar colours for clarity.

$$
\begin{aligned}
\frac{f S_{u}(f)}{u_{\star}^{2}} & =\frac{51 n}{(1+33 n)^{5 / 3}}, \\
\frac{f S_{v}(f)}{u_{\star}^{2}} & =\frac{8.5 n}{(1+9.5 n)^{5 / 3}}, \\
\frac{f S_{w}(f)}{u_{\star}^{2}} & =\frac{1.05 n}{1+5.3 n^{5 / 3}}, \\
\frac{f S_{u w}(f)}{u_{\star}^{2}} & =-\frac{6 n}{(1+9.6 n)^{7 / 3}} .
\end{aligned}
$$

The turbulence is enhanced when the flow is in the direction of Risø (first panel). The transverse component is especially enhanced in comparison to that of the longer fetch cases. There appears to be no shift in horizontal length scales for the incoming turbulence between the three fetch classes, because the maximum level for each individual component occurs 

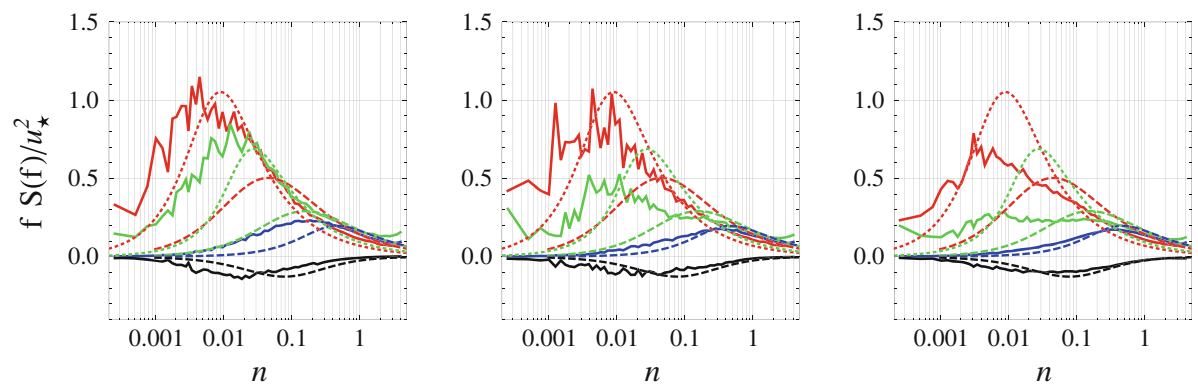

Fig. 6 Turbulence spectra at M0. The three panels represent the three fetch classes. The spectra are plotted in dimensionless units $f S(f) / u_{\star}^{2}$ as a function of $n=f z / u$. The four spectra plotted are $S_{u}(f)($ red $), S_{v}(f)$ (green), $S_{w}(f)$ (blue) and $S_{u w}(f)$ (black). The Kaimal model is plotted with the dashed lines in a similar colour code, while the ESDU spectra are plotted with dotted lines only for the two horizontal components

for similar $n$ in all three panels. For the vertical component, the length scale is reduced when the fetch is increased. The Kaimal spectra were obtained from the Kansas experiment (Izumi 1971) performed under nearly perfect flat, homogeneous conditions and at higher elevations above the terrain. We would therefore expect the data in fetch class three (right panel) to be closest, although remaining at larger levels in the streamwise direction due to the finite fetch length. In addition, we experienced the following patterns: for all wavenumbers, $n$, the streamwise component (red) was significant larger with the maximum occurring at a large integral scale (to the left). The transverse component (green) was more evenly distributed on all wavenumbers compared with the Kaimal spectrum, while the vertical component (blue) and the cospectrum were similar. We thus have a much more differentiated picture with a large gap (a factor of approximately 100) between the typical length scale of streamwise and vertical velocity fluctuations. The match for $w$ and $u w$ spectra with the Kaimal spectrum was probably caused by the overall local equilibrium at these scales bounded by the height. The larger streamwise integral scale in our data compared to the Kaimal spectrum could have been caused by several factors. The data from the Kansas experiment were high pass filtered $(5 \mathrm{~min})$, and hence large temporal fluctuation behaviour has been neglected. We have performed such high pass filtering only for the upper limit of 30-min of consecutive measurements in the statistics. In addition, one can consider the homogeneity of the terrain upstream of Bolund: with a 7-km fetch one could easily believe that measurements at $5 \mathrm{~m}$ above water would be similar to those measured over truly homogeneous terrain. Högström et al. (2001), however, determined that surfacelayer turbulence can be affected by detached eddies that originate from above the surface layer; hence, they are not in are not in local equilibrium with eddies created locally at the measuring site. If this case is correct, roughness changes of more than $7 \mathrm{~km}$ upstream could, in principle, affect the spectrum measured even at $5 \mathrm{~m}$ through advection of inactive eddies.

We have also plotted the Engineering Science Data Unit (ESDU) spectra (ESDU International 1985) for the horizontal components. ESDU proposes that turbulent length scales increase with wind speed. In addition, the non-local effect of a finite-height boundary layer is included. In the streamwise direction for the 7-km fetch, the ESDU spectrum, represented by the red dotted line, peaked at a similar or only slightly smaller length scale than that of our measurements. On the contrary, the variance is, approximately 50\% larger than measurements. We have also attempted to apply the RDT turbulence model in Mann (1994); however, the longitudinal spectra did not coincide with the model spectra. 


\section{Hill Measurements: Mean Quantities}

The two lines in Fig. 2 denoted as line A and line B are the two transects along which data are presented. Transect A is oriented along $239^{\circ}$, while transect B is oriented along $270^{\circ}$. Differences between the two transects exist. The shorter transect, A, is close to symmetric with the western edge slightly steeper than the eastern edge, while transect B has a more pronounced escarpment at the western edge and a more gentle slope on the eastern edge. As we will subsequently discuss minor differences exist when considering speed-up and the production of turbulent kinetic energy.

\subsection{Transect A}

We considered relative speed, that is, the horizontal speed at a given station and height divided by the horizontal speed at the reference mast, M0, at $5 \mathrm{~m}$. In all figures, the $x$-axis denotes wind direction of the incoming wind measured at M0. The use of the same reference, M0 at $5 \mathrm{~m}$, makes the definition of speed-up slightly different from that usually used. Data are presented in the left panels of Fig. 7. In the right panels, the normalized turbulence, $\sigma_{u} / \sigma_{u_{\mathrm{ref}}}$ is shown, where $\sigma_{u_{\mathrm{ref}}}$ is the measured standard deviation of $u$ from M0 at $5 \mathrm{~m}$ with a sonic anemometer. In Fig. 8, the associated tilt and deflection angles are presented. The tilt angle is measured in degrees with the horizontal denoting zero tilt angle. The deflection is relative to the incoming wind direction. For example, a measured deflection angle of $10^{\circ}$ for a wind direction of $200^{\circ}$ means that the wind direction at the anemometer is $210^{\circ}$.

For both figures and all panels, the different colours refer to various heights: 1, 2, 3, 5 and $9 \mathrm{~m}$ are represented by yellow, red, orange, green and blue, respectively. Each data point refers to neutral stratification. The vertical lines at each data point represent the mean deviation from neutral due to stability. Instead of including the neutral cases only, all measurements regardless of stability have been included. As seen in the histogram of $z / L_{\mathrm{M} 0}$ in Fig. 3 stable stratification is the most likely case while unstable stratification is rather rare. In Sect. 2.1 we stated that thermal stratification only has a minor effect compared to orographic perturbations. This finding is verified in figures where the deviation in most matters is either minor or non-existent.

Transect $\mathrm{A}$ is in the $239^{\circ}$ direction.

M1 Just in front of the hill, the flow was blocked, and a decrease in the wind speed centred near $239^{\circ}$ was observed. There was an increase in turbulence of around $20 \%$ for the lowest height, $2 \mathrm{~m}$ and slightly less for $5 \mathrm{~m}$, red and green, respectively. Positive tilt angles were observed for all wind directions, and the three-dimensional shape of Bolund was observed in the deflection plot with negative and positive deflection for values larger and smaller of $239^{\circ}$, respectively.

M2 At the hill-top mast, we observed nearly zero wind speeds close to the ground (yellow and red) accompanied by a large increase in the turbulence of a maximum factor of four. At greater heights, we observed discontinuous jumps with increasing wind direction, which indicates that the specific shape of the local topography has a significant impact on the flow. At $9 \mathrm{~m}$, the flow was nearly independent of wind direction with an average $20 \%$ speed-up. However, no increase in turbulence intensity was observed. Closest to the ground negative tilt was observed indicating that the mast was positioned close to the edge or near a small region of detached flow. 

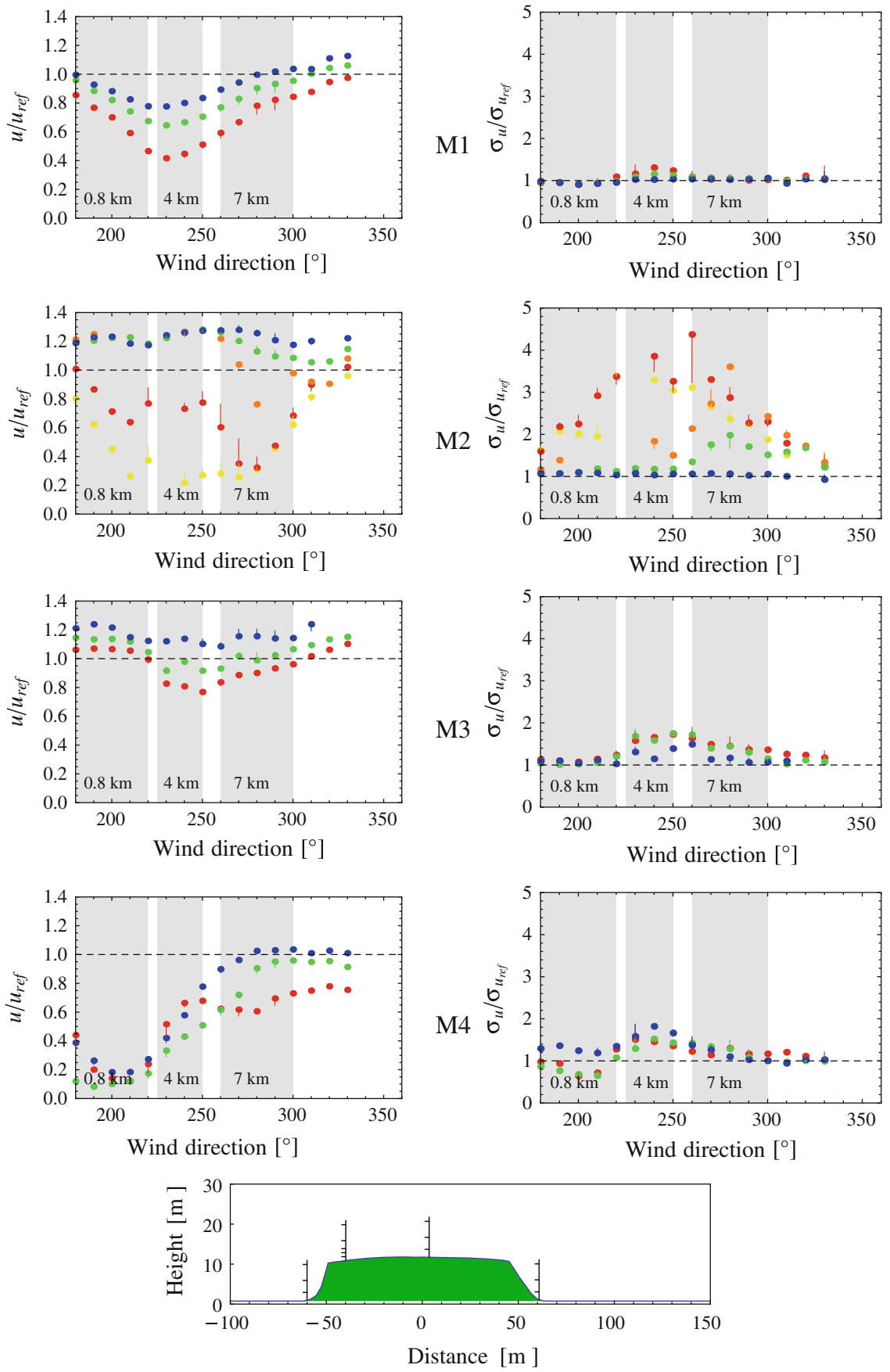

Fig. 7 Transect A: from top to bottom: M1, M2, M3 and M4. Left to right: speed-up and normalized turbulence intensity. Data for neutral stability are plotted with range of the other stability classes marked with vertical lines. The different colours refer to the various heights: $1,2,3,5$ and $9 \mathrm{~m}$ are represented by yellow, red, orange, green, blue, respectively. Bottom: height profiles of transect A at $239^{\circ}$ with masts M1, M2, M3, and M4. The distance on the horizontal axis is with reference to Mast M3 located close to (0, 0) in Fig. 2 

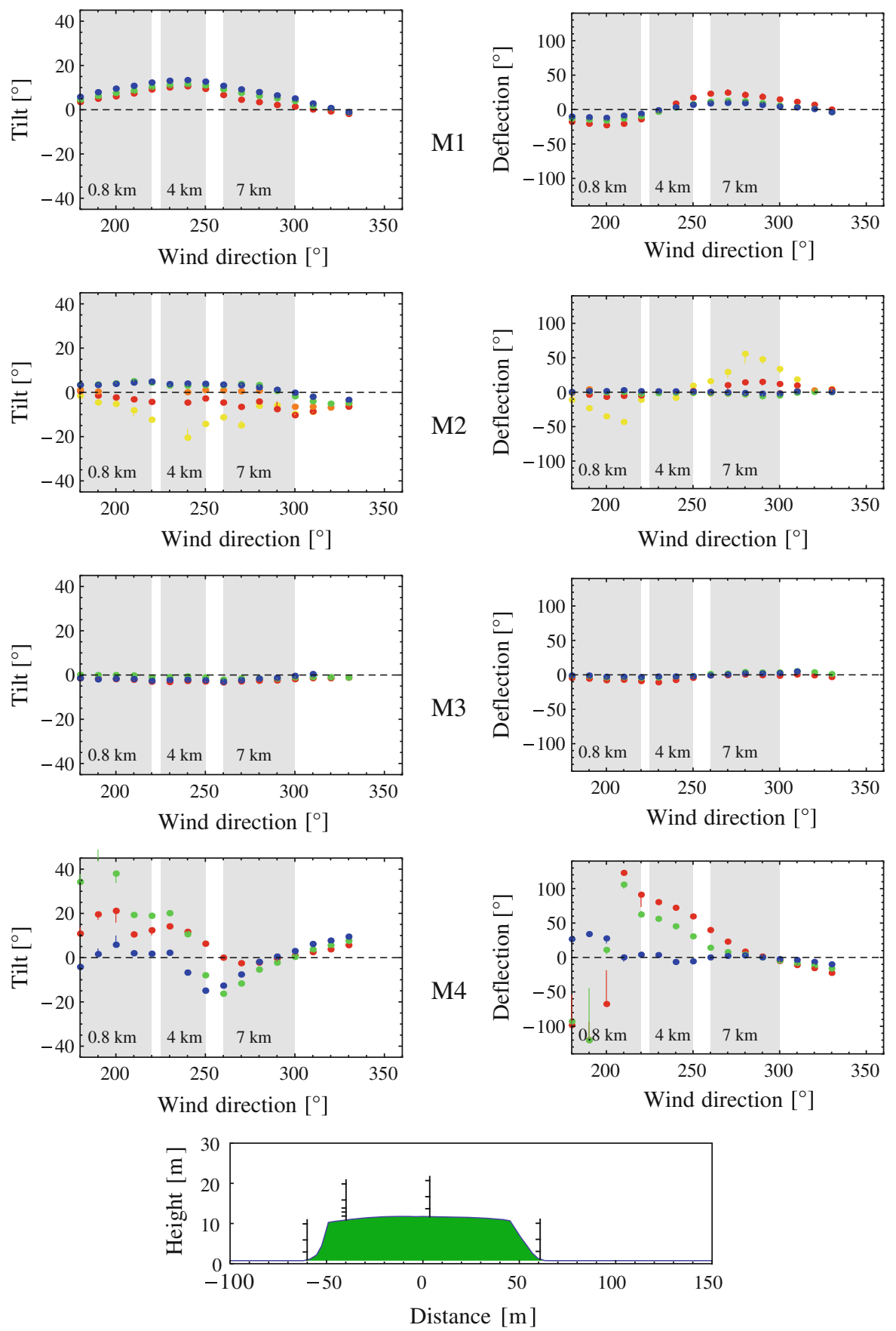

Fig. 8 Transect A: from top to bottom: M1, M2, M3 and M4. Left to right: tilt and relative deflection. Data for neutral stability are plotted with range of the other stability classes marked with vertical lines. The different colours refer to the various heights: 1, 2, 3, 5 and $9 \mathrm{~m}$ are represented by yellow, red, orange, green, blue, respectively. Bottom: height profiles of transect A at $239^{\circ}$ with masts M1, M2, M3 and M4. The distance on the horizontal axis is with reference to Mast M3 located close to $(0,0)$ in Fig. 2 
Mast M2 was positioned approximately $10 \mathrm{~m}$ from the western edge. Therefore, one might speculate that moving the mast just a few metres to one side will result in quite a different pattern. It is also interesting to observe that even at $5 \mathrm{~m}$ (green), the turbulence level remained nearly a factor of two larger than that of $\mathrm{M} 0$ from certain wind directions, indicating that the inner length scale, $\ell_{\mathrm{i}}=2 \mathrm{~m}$, does not fully characterize the viscous layer.

M3 At Mast M3 at the centre of the hill, the flow speed remained low for the transect direction near the surface, and the turbulence remained twice as large as that of the incoming level. The changing slope of the western edge was observed near $225^{\circ}$ in both panels. No tilt or deflection was observed.

M4 Mast M4 was placed just beyond the hill on the transect. On the lee side from $160^{\circ}$ to $230^{\circ}$, the flow was nearly blocked completely for all heights. The turbulence level remained moderate at up to $1.5 \sigma_{u_{\mathrm{ref}}}$ for all heights. As was previously discussed, the exact position of the mast could have a significant influence on the measured wind speed and turbulence. Similar to the case of M2, the flow pattern around M4 was more complex than illustrated here, and we will study these conditions in the future. The tilt was positive for all angles near $200^{\circ}$ up to $5 \mathrm{~m}$ with zero tilt at $9 \mathrm{~m}$. Again, this is a clear signature of a region with some type of detachment. The three-dimensional shape of Bolund is strongly manifested in deflection angles up to $5 \mathrm{~m}$.

\subsection{Transect B}

The data recorded along transect $\mathrm{B}$ (in the $270^{\circ}$ direction) are presented in a similar manner to that of transect A. The results can be seen in Figs. 9 and 10.

M7 The relative speed-down before the hill was quite significant with symmetry near the $250^{\circ}$ direction. In addition a slight increase in the turbulence intensity was observed. The tilt was positive and the deflection displayed a clear three-dimensional-shaped hill with a circumpolar flow most pronounced for the 2-m sonic measurements.

M6 This mast was positioned approximately $10 \mathrm{~m}$ from the escarpment. While speed-up was evident at $5 \mathrm{~m}$, nearly zero mean winds and a dramatic increase in turbulence was observed at $2 \mathrm{~m}$. Both speed-up and turbulence for the transect direction $\left(270^{\circ}\right)$ resemble the pattern observed at Mast M2 at transect A's direction $\left(239^{\circ}\right)$. This feature was reproduced with a slightly positive tilt aloft and a strong negative tilt close to the surface.

M3 Common to transect A and B, see description in Sect. 4.1.

M8 Beyond Bolund a large decrease in relative speed was observed in connection with an increase in turbulence. Compared with Mast M6 at the hill top, this increase in turbulence was largest for the sonic measurements at $5 \mathrm{~m}$. Compared with transect $\mathrm{A}$ the behaviour behind Bolund was less dramatic especially for the negative tilt angles that were mainly positive at Mast M4.

The position of Mast M9, was approximately $200 \mathrm{~m}$ east of Bolund on the isthmus or nearly one Bolund hill length. For true westerly winds, the mast was placed in the wake of Bolund. In this region, the speed was decreased with only $5 \%$ compared with the undisturbed flow at M0, while the normalized turbulence intensity increased by $10-14 \%$ (not shown). These differences in the reference mast measurements could also be signatures from the often exposed isthmus located to the east of Bolund and the west of Mast M9. 

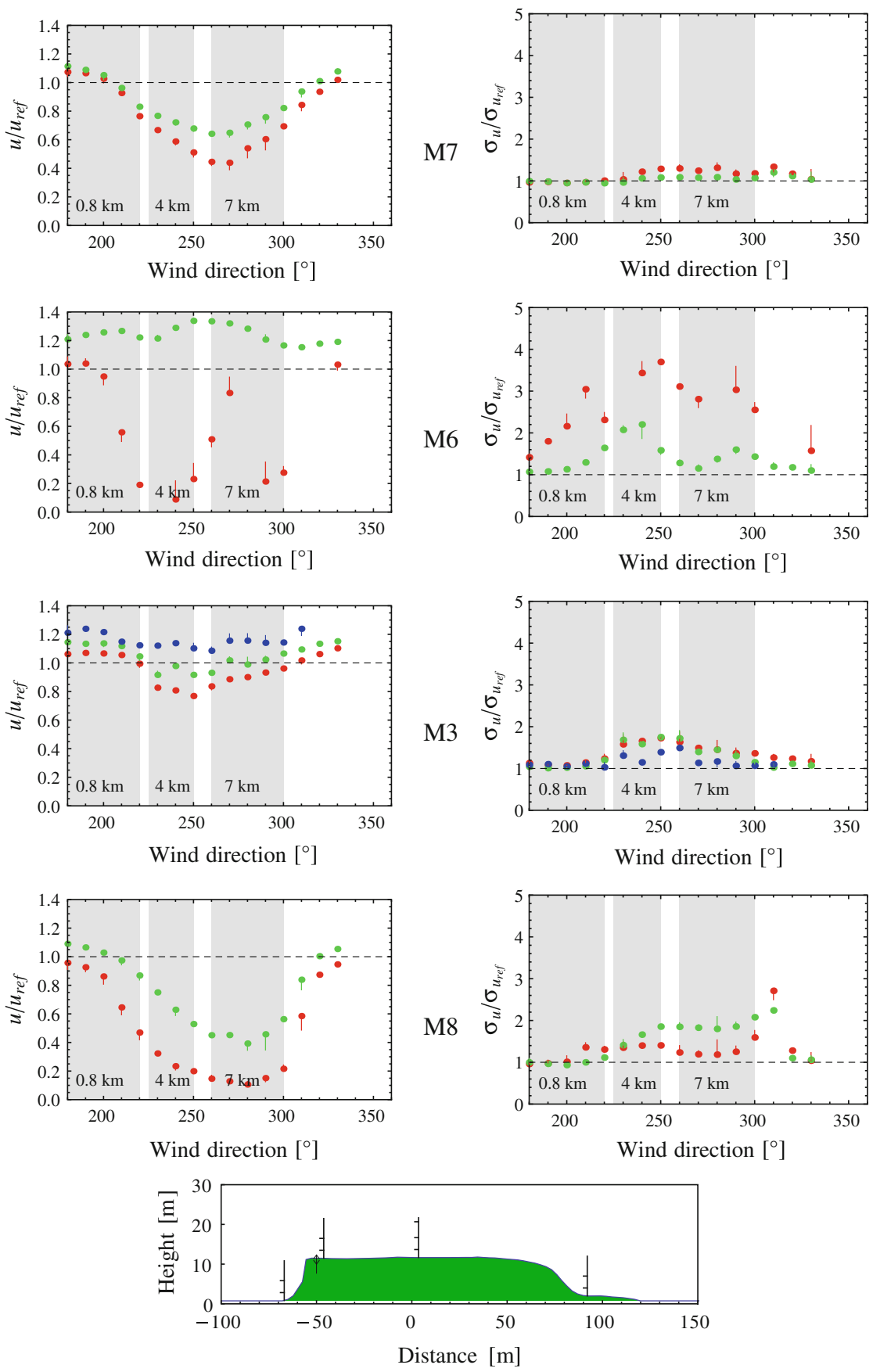

Fig. 9 Transect B: from top to bottom: M7, M6, M3 and M8. Left to right: speed-up and normalized turbulence intensity. Data for neutral stability are plotted with range of the other stability classes marked with vertical lines. The different colours refer to the various heights: 1, 2, 3, 5 and $9 \mathrm{~m}$ are represented by yellow, red, orange, green, blue, respectively. Height profiles of transect B at $270^{\circ}$ with masts M7, M6, M3 and M8. The distance on the horizontal axis is with reference to Mast M3 located close to $(0,0)$ in Fig. 2 

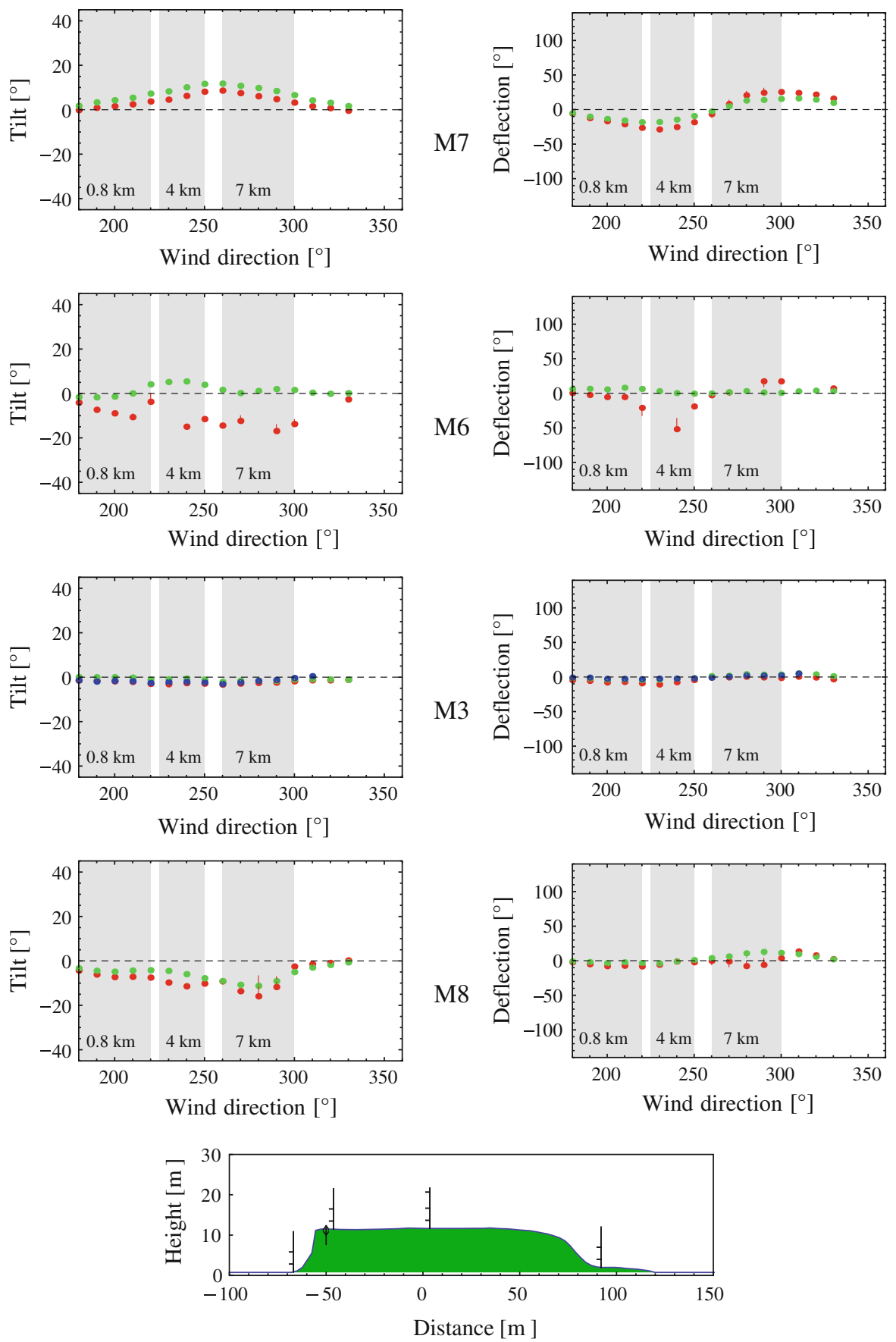

Fig. 10 Transect B: from top to bottom: M7, M6, M3 and M8. Left to right: tilt and relative deflection. Data for neutral stability are plotted with range of the other stability classes marked with vertical lines. The different colours refer to the various heights: 1, 2, 3, 5 and $9 \mathrm{~m}$ are represented by yellow, red, orange, green, blue, respectively. Height profiles of transect B at $270^{\circ}$ with masts M7, M6, M3 and M8. The distance on the horizontal axis is with reference to Mast M3 located close to $(0,0)$ in Fig. 2 


\section{Hill Measurements: Turbulent Structures}

From the mean turbulence at the two transects, we observed significantly enhanced levels as compared with the incoming turbulence levels measured at the upstream Mast M0. To gain more insight into the structure of this turbulence we present the spectra measured from the sonic time series sampled at $20 \mathrm{~Hz}$. As observed in Figs. 7 and 9, low wind speeds (left panels) are often accompanied by high variance, $\sigma_{u}$ (right panels), which violates Taylor's hypothesis. It is therefore impossible to interpret the spectra as signatures of pure spatial variability. For ease, we have therefore used the upstream velocity, and upstream surface friction velocity $u_{\star}$ as normalization constants. Hence, the spectra are plotted in dimensionless units $f S(f) / u_{\star, \text { ref }}^{2}$ as a function of $n=f z / u_{\text {ref }}$.

\subsection{Transect A}

The results along transect A are presented in Fig. 11. Data have been selected for an upstream wind direction of $239 \pm 5^{\circ}$, that is, along the transect itself.

M1 The form of the spectra observed at the three heights of 2, 5, and $9 \mathrm{~m}$ were similar with enhanced power closest to the surface. The variance was the largest in the streamwise direction (red) with maximum near $n=0.05$, while the vertical component (blue) peaked at yet smaller scales with higher $n$. The turbulent eddies were thus stretched in the horizontal direction. The cospectra were all close to zero with the $u^{\prime} w^{\prime}$ component (green) slightly negative corresponding to a negative momentum flux.

M2 Toward the hill top, the two sonics closest to the surface, at 1, and $2 \mathrm{~m}$, showed extremely high variance at scales yet smaller than that of M1. The peaks for the three directions occurred at nearly the same value of $n$ indicating a state toward isotropy. At $5 \mathrm{~m}$, the level of variance was decreased, however, the vertical component (blue) remained comparable in size to the streamwise component (red), albeit with a peak positioned at a much smaller scale. For the highest positions, 5 and $9 \mathrm{~m}$, the situation was calmer with only moderate levels of variance. The cospectra showed high negative values for the $u^{\prime} w^{\prime}$ component (green) closest to the surface. However, also the transverse component, $v^{\prime} w^{\prime}$ (blue), displayed negative values. The latter was probably caused by specific details of the local orography.

M3 At the centre of Bolund, a significant amount of turbulence existed for all heights. The spatial scales of the turbulence remained constant with respect to M2, however, the level of variance was decreased.

M4 Beyond the hill, the turbulence at $9 \mathrm{~m}$ was close to isotropic. At $5 \mathrm{~m}$, the streamwise component (red) only carried half the variance of the other two components but peaked at a similar value of $n$. At $2 \mathrm{~m}$, the peaks of the transverse and vertical components were shifted to higher values of $n$. A positive value of $u^{\prime} w^{\prime}$ (green) at $2 \mathrm{~m}$ indicates a net positive momentum flux associated with the turbulence at this level. Aloft all cospectra were positive at $5 \mathrm{~m}$, while the two main components $u^{\prime} w^{\prime}$ and $v^{\prime} w^{\prime}$ balanced each other at $9 \mathrm{~m}$.

\subsection{Transect B}

The results along transect A are presented in Fig. 11. Data have been selected for an upstream wind direction of $270^{\circ} \pm 5^{\circ}$. 

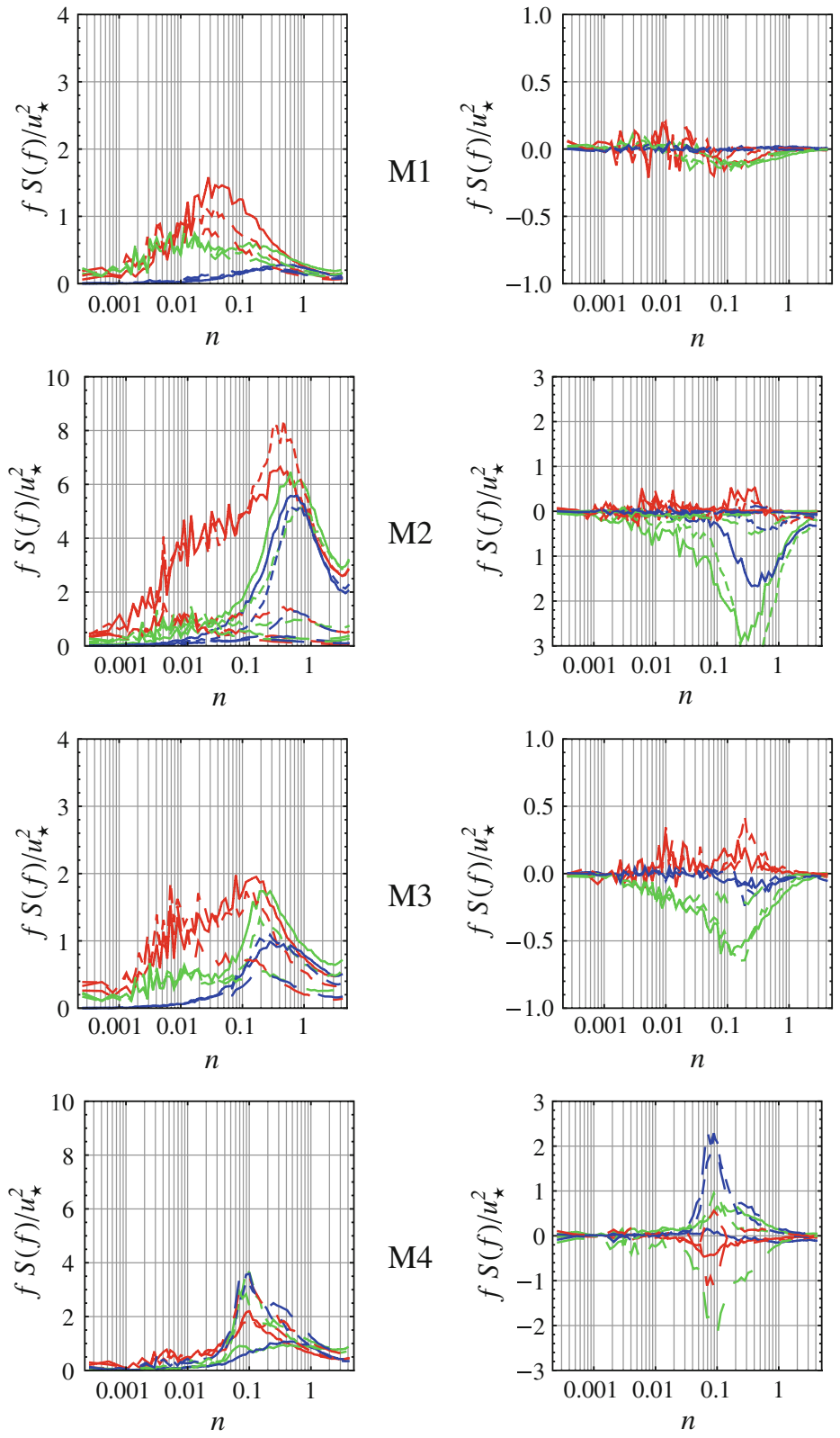

Fig. 11 Turbulence spectra along transect A for wind directions at $239^{\circ} \pm 5^{\circ}$ measured at M0 for neutral cases. The top panels through the bottom panels represent movement over the hill. The left panels show the spectra $S_{u}(f)$ (red), $S_{v}(f)$ (green) and $S_{w}(f)$, (blue) which are plotted in dimensionless units $f S(f) / u_{\star, \text { ref }}^{2}$ as a function of $n=f z_{\text {ref }} / u_{\text {ref }}$. The different dashing styles correspond to the various heights. Solid lines represent measurements close the surface while far-spaced dashed lines corresponds to measurements taken aloft. The reference velocities are measured at M0 in $5 \mathrm{~m}$. The right panels show cospectra $S_{u v}(f)$ (red), $S_{u w}(f)$ (green) and $S_{v w}(f)$ (blue). Different limits are evident on the vertical axes 
M7 The conditions at M7 were quite similar to that of M1, with the greatest variance in the streamwise direction peaking near $n=0.05$.

M6 At the hill top the turbulence was smaller than at M2. More striking, however, was the broad distribution of variance in the streamwise direction (red). Spanning two orders of magnitude in $n$, eddies of all sizes ranging from many times the size of Bolund to sizes much smaller contribute to the total variance. The very steep nearly vertical escarpment along this transect thus generated significantly complex structures that could not be easily characterized. This behaviour was accompanied by large negative values in the cospectra for $u^{\prime} w^{\prime}$.

M3 Compared with M3, no remarkable differences were observed with the wind direction along direction $239^{\circ}$.

M8 At M4, behind the gentle slope at the rear of the transect, the largest variance occurred closest to the ground in the streamwise direction. At $5 \mathrm{~m}$, approximately half the height of Bolund, the three components were nearly equal, indicating isotropic conditions. Large negative values of momentum flux were observed for both heights (Fig. 12).

\subsection{Reversed Flow}

The extreme high level of turbulence occurring at the hill top and partially beyond the Bolund hill indicate the presence of a mechanism greater than the possible inference from the 30-min averages of relative wind speed presented in Sect. 4. In addition the somewhat wide peak observed in the spectra at M2 on transect A close to the surface shows strong evidence of a continuum of time scales. In the left panels in Fig. 13 we present a 30-min time series recorded at M2 for $1 \mathrm{~m}$ of the wind speed, $u_{239}$, along the upstream mean wind direction, here, $\approx 239^{\circ}$, that is, along the transect. Recirculation or reversed flow of any type was manifested though negative $u_{239}$. For the given period the local mean was $2.3 \mathrm{~m} \mathrm{~s}^{-1}$. We, however, observed that in a substantial amount of time, the wind velocity was negative. The gusty nature of the flow was evident. The speed fluctuated to a great extent on time scales from seconds (lower panel) to half a minute (upper panel). The corresponding probability density function is given in the right panel of Fig. 13. The negative velocities were only measured close to the surface at $1 \mathrm{~m}$ and at $2 \mathrm{~m}$ (not shown), that is, within the inner layer, in approximately 22 and $3 \%$ of the time, respectively. Gaussian distributions were observed for all heights and the decrease of variance with height was evident (not shown).

At Mast M4 on transect A, positioned just beyond Bolund, we also encountered significantly high turbulence levels with reversed flow, albeit with lesser probability $(10 \%$ at $2 \mathrm{~m}$, $5 \%$ at $5 \mathrm{~m}$, and $0.3 \%$ at $9 \mathrm{~m}$ ) than at the hill top (Mast M2). Conversely, negative velocities extended to larger heights (not shown). This result was expected because the sonic anemometer was positioned below the hill height. A similar pattern of reversed flow existed along transect B.

\section{Conclusions}

We have attempted to present the most interesting flow features measured at Bolund. Although Bolund is small in size, the phenomena occurring can be generalized to much larger hills at least for cases with neutral stratification.

We argue that precise characterization of the upstream conditions is important. For the $7-\mathrm{km}$ fetch over water, the relationship between $z_{0}$ and $u_{\star}$ is well described by Charnock's 

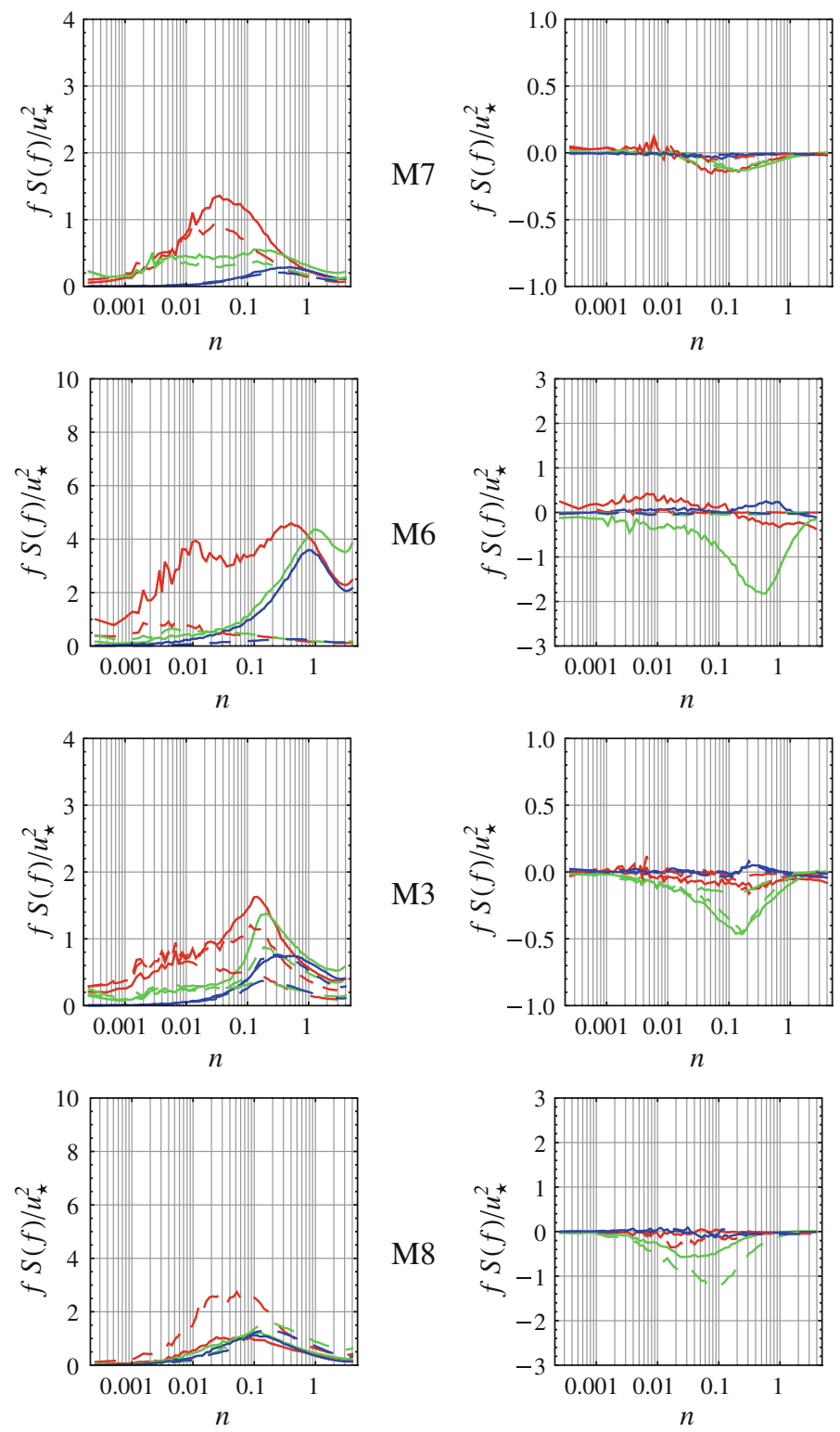

Fig. 12 Turbulence spectra along transect B, as detailed in the caption of Fig. 11

relation and the wind profile is logarithmic. The wind profile is established from cup anemometers at several heights dependent on fetch and stability. The turbulence spectra are compared with both Kaimal spectra and ESDU. In the streamwise and horizontally transverse directions the measured spectra do not compare with traditional forms, which we attribute to non-local effects and insufficiently low measurements heights. We also highlight the non-zero transverse momentum flux $\left\langle v^{\prime} w^{\prime}\right\rangle$. The positive sign could indicate that the Coriolis force even in such close proximity to the surface is important. 

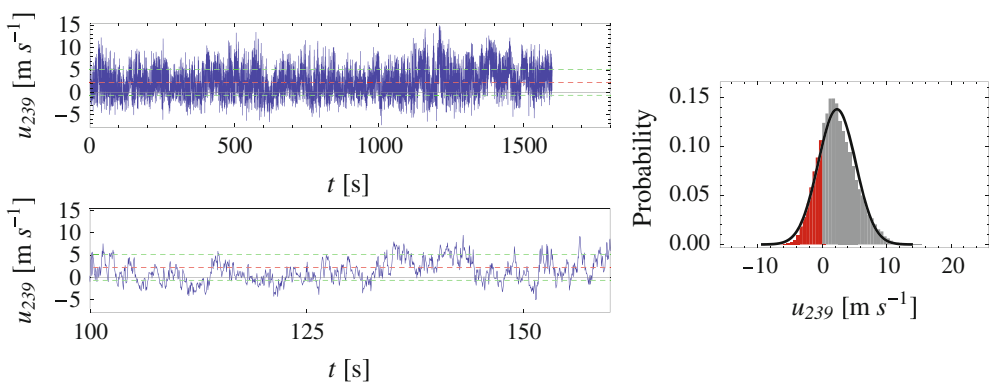

Fig. 13 Left: time series of $u_{239}$ at Mast M2 in $1 \mathrm{~m}$. Data are sampled at $20 \mathrm{~Hz}$ corresponding to 36,000 timesteps for $30 \mathrm{~min}$. Top left: $30 \mathrm{~min}$. Bottom left: $1 \mathrm{~min}$. The red horizontal line represents the mean while the green lines represent the standard deviation. Right: probability density function of $u_{23}$ at Mast M2 at $1 \mathrm{~m}$. A Gaussian fit is presented as a solid black line

From measurements of wind speed, turbulence and flow angles from various wind directions, we have observed that the flow is quite sensitive to even the slightest change in height, which is illustrated in Fig. 8. For the measurements close to the ground, the flow is also to some degree sensitive to changes in terrain. From a modelling perspective this indicates that very high resolution probably much finer than $1 \mathrm{~m}$, should be used. Another important consequence of the sensitivity is that if we had moved the masts several metres in various directions or placed the sonic instruments at slightly different heights, the measurements may have registered different results, which could perhaps change the quantitative conclusions of speed-up and turbulence for the various heights. This finding is especially true for the measurements at the hill top, M2 and M6, and those beyond Bolund, M4 and M8, which were located in regions of high turbulence levels. In Bechmann et al. (2011), this sensitivity is evident from the various model studies.

At the hill top the speed-up was accompanied by extreme turbulence levels. A speed-up of approximately 30\%, as observed at M2 and illustrated in Fig. 7, is comparable with data from Askervein Hill. On the contrary, the corresponding turbulence level of approximately four times the upstream level is beyond any documented hill experiment, which implies that the best site relative to wind-energy resources unfortunately also implies greatly enhanced dynamic loads.

Closer inspection of the turbulence revealed significant reverse flow close to the surface. To predict such unsteady flow structures, models capable of resolving both spatial and temporal structures of turbulence are necessary. Even near one Bolund hill length, $L$, the downstream flow showed signs of enhanced turbulence, although the mean wind speed had generally relaxed to its upstream value. The inner length scale, $\ell_{\mathrm{i}}$, predicted by the linear flow theory, was estimated to $2 \mathrm{~m}$. We, however, observed a substantial amount of turbulence even at heights larger than, $\ell_{\mathrm{i}}$. An example of this phenomenon was observed at Mast M3 at the centre of Bolund, where the normalized turbulence intensity was constant up to a minimum of $5 \mathrm{~m}$. Therefore the inner length scale is not a characteristic length scale of the flow near Bolund, as we expected.

Through these observations, it is clear that the linear theory is not applicable. In a modelling context, this would indicate that a simple solution with a linear model may provide no insight. In addition non-linear models of the RANS type that currently are widely used in both industry and academia, also are not likely to be perfectly suited because they lack both time dependence and realistic representation of turbulence (spatial structure). LES models appear to be the most promising candidates. With time, we expect LES models to 
successfully simulate a complex flow such as the one reported here. Again, spatial resolution is very important. Whereas inflow turbulence is often mentioned as a crucial factor for making an effective LES model (Bechmann and Sørensen 2010), this factor does not appear to be of such great importance at Bolund due to the extreme level of turbulence created by the presence of Bolund itself. As documented in Bechmann et al. (2011), LES models encounter additional problems relative to modelling the flow near Bolund.

In retrospect, several steps could have been performed differently. Instead of working with two transects, we could have focused on only one with more dense instrumentation, which would have allowed us to study the size of the recirculation zone on the hill top and the wake beyond the hill. In addition, positioning the sonic instruments in front of the hill and in its wake at higher heights, at least comparable to the height of Bolund, would have been desirable. We strongly urge researchers who are interested in the technical aspects of the measurement campaign to consult the Risø DTU report (Bechmann et al. 2009) for details.

Future experiments on boundary-layer flow in complex terrain should address the issue of stratification. Much larger hills, as well as measurement techniques that can sample a large part of the boundary layer are necessary. The lidar wind scanner (Mikkelsen et al. 2008) is a prominent candidate for this study. New types able to measure smaller scale turbulence are in the development stage and could be of great assistance. Such new techniques would allow for a three-dimensional scan over a hill; thus, a more complete picture that obtained from anemometers at fixed positions could be possible.

Acknowledgments We would like to thank the Danish energy agency (EFP07—Metoder til kortlægning af vindforhold i komplekst terræn (ENS-33033-0062)), the Center for Computational Wind Turbine Aerodynamics and Atmospheric Turbulence (under the Danish Council for Strategic Research, Grant no. 09-067216), and Vestas Technology R\&D for financial support. We would also like to thank former Ris $\varnothing$ DTU employee Jeppe Johansen who developed the concept of a field campaign at Bolund and initiated the project together with co-author Hans E. Jørgensen. Without the aid from technicians in the Test and Measurement Section in the Wind Energy Division at Risø DTU as well as all Risø DTU employees who helped to carry masts and instruments to Bolund, the project would not have been possible. All data were collected in a MySQL database, which will be available to the public in the near future.

\section{References}

Athanassiadou M, Castro IP (2001) Neutral flow over a series of rough hills: a laboratory experiment. Boundary-Layer Meteorol 101(1):1-30

Ayotte KW, Hughes DE (2004) Observations of boundary-layer wind-tunnel flow over isolated ridges of varying steepness and roughness. Boundary-Layer Meteorol 112(3):525-556

Bechmann A, Sørensen NN (2010) Hybrid RANS/LES method for wind flow over complex terrain. Wind Energy 13(1):36-50

Bechmann A, Berg J, Courtney MS, Jørgensen HE, Mann J, Sørensen NN (2009) The Bolund experiment: overview and background. Ris $\varnothing$ DTU report Ris $\varnothing-R-1658(E N)$, pp 1-50

Bechmann A, Sørensen NN, Berg J, Mann J, Réthoré P-E (2011) The Bolund experiment, part II: blind comparison of microscale flow models. Boundary-Layer Meteorol. doi:10.1007/s10546-011-9637-x

Britter RE, Hunt JCR, Richards KJ (1981) Air flow over a two-dimensional hill: studies of velocity speed-up, roughness effects and turbulence. Q J Roy Meteorol Soc 107:91-110

Castro IP, Robins AG (1997) The flow around a surface-mounted cube in uniform and turbulent streams. J Fluid Mech 79:307-335

Castro FA, Palma JMLM, Lopez AS (2003) Simulation of the Askervein flow. Part i: Reynolds averaged Navier-Stokes equation. Boundary-Layer Meteorol 107:501

Charnock H (1955) Wind stress on a water surface. Q J Roy Meteorol Soc 81:639-640

Chow FK, Street RL (2009) Evaluation of turbulence closure models for large-eddy simulation over complex terrain: flow over Askervein Hill. J Appl Meteorol Climatol 48(5):1050-1065 
Corbett JF, Ott S, Landberg L (2008) A mixed spectral-integration model for neutral mean wind flow over hills. Boundary-Layer Meteorol 128:229

Dellwik E, Mann J, Larsen KS (2010a) Flow tilt angles near forest edges-part 1: sonic anemometry. Biogeosciences 7:1745-1757

Dellwik E, Mann J, Larsen KS (2010b) Flow tilt angles near forest edges_part 2: lidar anemometry. Biogeosciences 7:1759-1768

Emeis S, Courtney MS, Højstrup J, Jensen NO (1993) Hjardemål experiment data report. Technical report. Risø National Laboratory, Denmark

ESDU International (1985) Characteristics of atmospheric turbulence near the ground. Part II: Single point data for strong winds (neutral atmosphere). ESDU (Engineering Sciences Data Unit) International, London

Geernaert GL (1997) On the importance of the drag coefficient in air-sea interactions. Dyn Atmos Oceans $1: 19$

Högström U, Hunt JCR, Smedman AS (2001) Theory and measurements for turbulence spectra and variance in theory atmospheric neutral surface layer. Boundary-Layer Meteorol 103:101-124

Hunt JCR, Abell CJ, Peterka JA, Woo H (1978) Kinematical studies of the flows around free or surfacemounted obstacles; applying topology to flow visualization. J Fluid Mech 86:179-200

Hunt JCR, Leibovich S, Richards KJ (1988) Turbulent shear flows over low hills. Q J Roy Meteorol Soc 114:1435

Izumi Y (1971) Kansas 1986. Field program data report. AFCRL environmental research papers no. 379. Technical report. Air force Cambridge Research Laboratories, L. G. Hanscom Field, Bedford, USA, $79 \mathrm{pp}$

Jackson PS, Hunt JCR (1975) Turbulent wind flow over a low hill. Q J Roy Meteorol Soc 101:929

Jensen NO, Peterson EW (1978) Escarpment wind profile. Q J Roy Meteorol Soc 104(441):719-728

Jensen NO, Petersen EL, Troen I (1984) Extrapolation of mean wind statistics with special regard to wind energy applications. WMO-WCP 86, World Climate Programme, WMO, Geneva, Switzerland

Kaimal JC, Finnigan JJ (1994) Atmospheric boundary layer flows. Oxford University Press, Oxford

Lim HC, Castro IP, Hoxey RP (2007) Bluff bodies in deep turbulent boundary layers: Reynolds-number issues. J Fluid Mech 571:97-118

Lopes AS, Palma JMLM, Castro FA (2007) Simulation of the Askervein flow. Part 2: Large-eddy simulations. Boundary-Layer Meteorol 125(1):85-108

Mann J (1994) The spatial structure of neutral atmospheric surface-layer turbulence. J Fluid Mech 273: $141-168$

Mann J (2000) The spectral velocity tensor in moderately complex terrain. J Wind Eng Ind Aerodyn 88: 153-169

Metek (2004) Flow distortion correction for 3-d flows as measured by METEK's ultrasonic anemometer USA-1. Technical report, Metek, GmbH

Mikkelsen T, Mann J, Courtney MS, Sjöholm M (2008) Windscanner: 3-D wind and turbulence measurements from three steerable Doppler lidars. IOP conference series: earth and environmental science, vol 1, p 012018

Palma JMLM, Castro FA, Ribeiro LF, Rodrigues AH, Pinto AP (2008) Linear and nonlinear models in wind resource assessment and wind turbine micro-sitting in complex terrain. J Wind Eng Ind Aerodyn 96(12):2308-2326

Pope SB (2000) Turbulent flows. Cambridge University Press, UK, 770 pp

Sacré C (1979) Experimental-study of the air-flow over a hill in the atmospheric boundary-layer. BoundaryLayer Meteorol 17(3):381-401

Taylor P, Teunissen HW (1983) Askervein '82: report on the September/October 1982 experiment to study boundary-layer flow over Askervein, South Uist. Ontario technical report MSRB-83-8. Atmospheric Environment Service, Downsview

Taylor P, Teunissen H (1984) The Askervein Hill project: report on the Sept./Oct. 1983, main field experiment. Ontario technical report MSRB-84-6. Atmospheric Environment Service, Downsview

Taylor PA, Mason PJ, Bradley EF (1987) Boundary-layer flow over low hills. Boundary-Layer Meteorol 39:107

Troen I, Petersen EL (1989) European Wind Atlas. Risø National Laboratory, Roskilde, Denmark, 656 pp

Walmsley JL, Taylor PA (1996) Boundary-layer flow over topography: impacts of the Askervein study. Boundary-Layer Meteorol 78:291-320 